\title{
Studies on the decontamination of
}

\section{surfaces exposed to cytotoxic drugs in chemotherapy workstations}

\section{Sewell, GJ}

http://hdl.handle.net/10026.1/3724

\section{$10.1177 / 1078155206070439$ \\ Journal of Oncology Pharmacy Practice \\ SAGE Publications}

All content in PEARL is protected by copyright law. Author manuscripts are made available in accordance with publisher policies. Please cite only the published version using the details provided on the item record or document. In the absence of an open licence (e.g. Creative Commons), permissions for further reuse of content should be sought from the publisher or author. 


\title{
Studies on the decontamination of surfaces exposed to cytotoxic drugs in chemotherapy workstations
}

\author{
Sarah Roberts, Bsc ${ }^{1}$ \\ Nancy Khammo, $P h D^{2}$ \\ Gerald McDonnell, $P h D^{2}$ \\ Graham J Sewell, PhD, BPharm ${ }^{3}$
}

Objective. The aim of this study was to examine the removal and deactivation of cytotoxic contamination from surfaces of a pharmaceutical isolator workstation.

Methods. Three marker cytotoxic drugs were evaluated in three phases using decontamination technologies currently available in the pharmaceutical and healthcare environments. Phase I investigated the physical removal of contamination by detergents. Phase II and III investigated the effectiveness of detergents and Vaporised Hydrogen Peroxide (VHP ${ }^{(B)}$ in degrading cytotoxic drugs, respectively.
Results. 5-Flurouracil, doxorubicin and cyclophosphamide were removed from a surface by wiping with detergents. VHP ${ }^{(B)}$ and alkaline detergents caused degradation of doxorubicin. The observed effect with detergent cleaning was pH dependent, but neither of the technologies applied had any effect on the chemical stability of 5-flurouracil and cyclophosphamide under the conditions tested. $J$ Oncol Pharm Practice (2006) 12: 95-104.

Key words: cyclophosphamide; cytotoxic; decontamination; degradation; doxorubicin; 5-flurouracil; vaporized hydrogen peroxide

\section{INTRODUCTION}

Chemotherapy is the only systemic treatment modality for cancer. However, cytotoxic drugs are not selective for cancer cells, but also effect the growth and reproduction of healthy cells. During the preparation of cytotoxic infusions, a variety of drug manipulations are performed, resulting in the generation of aerosols and droplets, which are known to contaminate the areas in which they disperse into, including isolators and surrounding surfaces. ${ }^{1-9}$ This

From the ${ }^{1}$ Department of Pharmacy and Pharmacology, University of Bath, Bath, UK; ${ }^{2}$ Steris Ltd, Basingstoke, Hampshire, UK; ${ }^{3}$ Department of Pharmacy, Kingston University, Kingston-UponThames, Surrey, UK

Address correspondence and reprint requests to Professor GJ Sewell, Department of Pharmacy, Kingston University, Penrhyn Road, Kingston, Surrey, KT1 2EE, UK

E-mail: g.j.sewell@kingston.ac.uk

Received 1 March 2006; accepted 12 June 2006 increases the risk of occupational exposure to these drugs, for which the health effects are well documented. ${ }^{10-13}$

The effectiveness of removing cytotoxic residues from surfaces during cleaning is not often considered. Ideally, removing cytotoxic contamination should involve the physical removal of drug contamination from a surface and drug breakdown into less toxic compounds. Cytotoxic drugs represent a diverse range of chemical structures, and no single agent is known to deactivate all the cytotoxic drugs currently used. Therefore, decontamination is limited to the mechanical removal from a non-disposable surface to a disposable surface, ie, by wiping the working surface with a cleaning agent. The National Institute for Occupational Health and Safety (NIOSH) recommends that all surfaces are decontaminated according to a protocol, which includes an appropriate deactivation agent if available. ${ }^{14}$ The agent used should preferably demonstrate removal/breakdown 
of biological and chemical contamination. ${ }^{14}$ Currently, the most prevalent practice consists of surface wiping with water, with or without a detergent, with thorough rinsing, followed by wiping with $70 \%$ alcohol.

In 1985, the International Agency for Research on Cancer (IARC) included cytotoxic drugs in its program for the treatment of contaminated waste, ${ }^{15}$ and oxidation was suggested as a method for degrading these compounds. Studies carried out to investigate the efficacy of oxidizing agents used in hospitals showed sodium hypochlorite $(5.25 \%)$ was $>99.96 \%$ efficient at degrading several drugs, including cyclophosphamide and doxorubicin. Liquid hydrogen peroxide $(30 \%)$ was also successful. ${ }^{16,17}$

The aim of this study was to investigate the safe decontamination of areas used for the dispensing of cytotoxic drugs, by evaluating systems that remove and deactivate cytotoxic contamination from the surface of an isolator workstation. Decontamination may be defined as the use of physical and/or chemical means to render a surface or item safe for handling, use or disposal. This can refer to both chemical and biological decontamination, which are important in the safe dispensing of cytotoxic drugs. Decontamination is generally a combination of cleaning (to physically remove surface contamination) and disinfection/sterilization (which are anti-microbial processes).

The effects of two decontamination technologies currently in practice, ie, vaporised hydrogen peroxide $\left(\mathrm{VHP}^{\circledR}\right)$ and liquid detergents, on three marker cytotoxic drugs were evaluated.

VHP ${ }^{\circledR}$ is an odourless, colourless gas that is produced by vaporization of liquid hydrogen peroxide to give a mixture of hydrogen peroxide and water vapour. The systems used to generate $\mathrm{VHP}^{\circledR}$ were based on the delivery of a 'dry' (or noncondensed) hydrogen peroxide gas within a given area. ${ }^{18}$ In this gaseous state, the biocidal and surface compatibility properties are markedly superior to liquid hydrogen peroxide. ${ }^{19}$ The liquid detergents were formulations scientifically designed for the removal of specific material, eg, protein- or mineralbased material from various surfaces, and are in current use for various hospital and pharmaceutical applications.

The decontamination of cytotoxic drugs on surfaces using the decontamination technologies currently available was investigated. The aim was not only to investigate the removal of the drugs, but also the effects of detergents and biocides tested in the interaction or break-down of the drugs into safe byproducts. This was evaluated in three phases:

Phases I and II investigated the effectiveness of aqueous-based detergents across a $\mathrm{pH}$ range of 1.713.2, as cleaning agents, which could be incorporated into a cleaning protocol;

Phase I - The physical removal of contamination from a surface by wiping with the detergents;

Phase II - The ability of the detergents as deactivating agents.

Phase III investigated the ability of $\mathrm{VHP}^{\circledR}$ to degrade the drugs on an inert surface by oxidation.

The three marker cytotoxic drugs used in this study were from different drug classes: 5-fluorouracil (5-FU, an anti-metabolite), cyclophosphamide (CP, an alkylating agent) and doxorubicin (DOX, an anthracycline antibiotic). These drugs are commonly used in the treatment of cancer and their sensitivity to degradation by various mechanisms is well documented.

\section{MATERIALS}

5-FU $(250 \mathrm{mg} / 10 \mathrm{~mL})$ and DOX $(2 \mathrm{mg} / \mathrm{mL})$ were obtained from Mayne Pharma Plc (Leamington Spa, UK); CP (500 mg) was obtained from Pzifer Ltd (Sandwich, UK). The test surface used in this study was made 'in-house' from the barrel of polypropylene syringes (Beckton and Dickinson, UK). Centrifuge (15 $\mathrm{mL}$ ) tubes were obtained from Sarstedt (Leics, UK). Liquid hydrogen peroxide (Vaprox $\left.{ }^{\circledR}\right)$, VHP 100P generator (Serial No. 0135103-29), flexible walled isolator, chemical indicators (Chemdi VHP code: NB305), and detergents (CIP 100, CIP 150, CritiKlenz, Renu-Klenz, NpH-Klenz, Cage-Klenz 250, CIP 200 and CIP 220) were supplied by STERIS Corporation (Basingstoke, UK). Acetonitrile, disodium hydrogen orthophosphate, methanol, potassium dihydrogen orthophosphate were purchased from Fisher Scientific (Leics, UK). Ammonium sulphate, perchloric acid, sodium chloride and sulphuric acid were purchased from $\mathrm{BDH}$ (Poole, UK). Normal saline (NS) and sterile water for injections (WFI) were obtained from Baxter (Newbury, UK). Industrial methylated spirit (IMS) was obtained from Shield Medicare (Surrey. UK). All chemicals and reagents used for high-performance liquid chromatography (HPLC) were of analytical grade or (HPLC) grade. Hydrogen peroxide detection tube and hand held pump (Accuro ${ }^{\circledR}$ ) were obtained from Dräeger (UK). The HPLC system comprised of an isocratic 
constaMetric 3200 pump (LDC analytical), autosampler 851-AS (Jasco) and a variable wavelength UV detector (Applied Biosystems). Data analysis was performed using Prime software, version 4.2.0 (HPLC Technology, Herts, UK). HPLC columns were purchased from Phenomenex (Cheshire, UK) and HPLC Technology (Herts, UK).

\section{METHODOLOGY}

Cytotoxic drug preparations, surface coating of test surfaces and Phase I and II of the study were carried out in a class II biological safety cabinet (BSC). Exposure of the drug to $\mathrm{VHP}^{\circledR}$ was carried out in a flexible-walled isolator.

\section{Choice of diluent}

All three marker drugs were reconstituted or diluted in two common clinical diluents; WFI, NS and the HPLC buffer specific for each drug assay, ie, phosphate buffer (0.01 M, pH 7.0) was used for 5-FU; ammonium sulphate buffer $(0.01 \mathrm{M}, \mathrm{pH} 3.5)$ was used for $\mathrm{CP}$; and sodium chloride $(0.01 \mathrm{M}, \mathrm{pH} 2.25)$ was used for DOX, to study any $\mathrm{pH}$ effect. Phase I, which involved removal by wiping was carried out on the drugs diluted in WFI and NS. In Phase II tests, WFI was used, and for Phase III, all diluents were used. Method validation was carried out with all diluents to take into account any variation in HPLC detector response.

\section{Drug reconstitution}

All cytotoxic drugs were diluted or reconstituted to the working concentration. 5-FU $(25 \mathrm{mg} / \mathrm{mL})$ was diluted in all three diluents to give a final concentration of $5 \mathrm{mg} / \mathrm{mL}$, and $10 \mu \mathrm{L}$ was transferred onto the test surface. The final concentration for assay was $10 \mu \mathrm{g} / \mathrm{mL}$. CP (500 mg) was reconstituted in all three diluents to give a final concentration of $20 \mathrm{mg} / \mathrm{mL}$, and $20 \mu \mathrm{L}$ was transferred onto the test surface. The final concentration for assay was $400 \mu \mathrm{g} / \mathrm{mL}$. DOX (2 mg/mL) was diluted to $1 \mathrm{mg} / \mathrm{mL}$ in all three diluents, and $10 \mu \mathrm{L}$ was transferred onto the tent aurface. The final concentration for assay was $10 \mu \mathrm{g} / \mathrm{mL}$.

\section{Test surface coating}

The test surface was made by transverse sectioning through a barrel of a $5-\mathrm{mL}$ polypropylene syringe at $2-\mathrm{cm}$ intervals. The resulting rings were then cut in half, giving rectangular surfaces of $2 \times 1.2 \mathrm{~cm}$. Polypropylene, an inert surface, was usede to eliminate any contribution from the surface on the tests carried out. The surfaces were coated by placing between 10 and $20 \mu \mathrm{L}$ of drug solution on the concave side of the surface. Surface controls included coating with diluent only and blank non-coated surfaces. All test surfaces (including blank) were allowed to dry in the BSC for 2 hours (until no solution remained). For Phase I, the surfaces were treated in the BSC and for Phase III, the surfaces were placed horizontally in the centre of the isolator, on a flat plastic tray, elevated at approximately $30 \mathrm{~cm}$ above ground level.

\section{Drug recovery}

Each test surface was placed into a centrifuge tube containing HPLC buffer specific for each drug (described in choice of diluent). The tubes were centrifuged for 5 minutes at $1500 \times g$. The supernatant was transferred to an autosampler vial for assay by HPLC. Recovery was determined at the experimental sample concentration. The desorption of dried drug from the polypropylene test surface into the desorbing solution (HPLC buffer) was measured against a standard (taken as 100\%) which had not been subjected to these conditions (Table 1).

\section{HPLC methods}

HPLC methods, ${ }^{20-22}$ were validated and used to quantify the amount of the parent drug remaining after all three study phases. For each assay, the flow rate was $1 \mathrm{~mL} / \mathrm{min}$, and $100 \mu \mathrm{L}$ was injected onto the column.

5-FU: Columbus C18, $5 \mu \mathrm{m}, 150 \times 4.6 \mathrm{~mm}$ column and $0.01 \mathrm{M}$ phosphate buffer ( $\mathrm{pH} 7.0$ ) containing $5 \%$ methanol as the mobile phase. A wavelength of $270 \mathrm{~nm}$ was used.

DOX: Techsphere $\mathrm{C}_{18}, 5 \mu \mathrm{m}, 150 \times 4.6 \mathrm{~mm}$ column and $0.01 \mathrm{M}$ sodium chloride buffer ( $\mathrm{pH} 2.25$ ) containing $40 \%$ acetonitrile as the mobile phase. A wavelength of $254 \mathrm{~nm}$ was used.

CP: Techsphere CN, $5 \mu \mathrm{m}, 250 \times 4.6 \mathrm{~mm}$ column and $0.01 \mathrm{M}$ ammonium sulphate buffer ( $\mathrm{pH} 3.5)$ containing $30 \%$ methanol as the mobile phase. A wavelength of $210 \mathrm{~nm}$ was used.

HPLC method validation results for each assay in all three diluents are shown in Table 1.

Precision was measured as the coefficient of variation (cv) of the experimental sample concentration. Five samples were prepared and assayed on the same day (intra-day) and one sample was prepared and analysed on 5 separate days (inter-day) by HPLC. Precision was accepted if $\mathrm{cv}> \pm 15 \%$. ${ }^{23}$ 
Table 1. HPLC method validation results for 5-FU, DOX and CP in three diluents

\begin{tabular}{|c|c|c|c|}
\hline & \multicolumn{3}{|c|}{ Cytotoxic drug } \\
\hline & $5-\mathrm{FU}$ & DOX & $\mathrm{CP}$ \\
\hline Limit of detection & $0.2 \mu \mathrm{g} / \mathrm{mL}^{\mathrm{a}}$ & $0.25 \mu \mathrm{g} / \mathrm{mL}^{\mathrm{a}}$ & $2.5 \mu \mathrm{g} / \mathrm{mL}^{\mathrm{a}}$ \\
\hline Limit of quantification & $0.5 \mu \mathrm{g} / \mathrm{mL}^{\mathrm{a}}$ & $1 \mu \mathrm{g} / \mathrm{mL}^{\mathrm{a}}$ & $10 \mu \mathrm{g} / \mathrm{mL}^{\mathrm{a}}$ \\
\hline Mean recovery $(n=5)$ & $\begin{array}{l}\mathrm{NS}=95.9 \% \\
\mathrm{WFI}=98.8 \% \\
\text { Buffer }=98.5 \%\end{array}$ & $\begin{array}{l}\text { NS }=99.9 \% \\
W F I=99.8 \% \\
\text { Buffer }=100.0 \%\end{array}$ & $\begin{array}{l}\text { NS }=100.4 \% \\
W F I=96.0 \% \\
\text { Buffer }=96.3 \%\end{array}$ \\
\hline Linearity regression coefficient & $\begin{array}{l}\text { NS: } R^{2}=0.999 \\
\text { WFI: } R^{2}=0.999 \\
\text { Buffer: } R^{2}=0.999\end{array}$ & $\begin{array}{l}\text { NS: } R^{2}=0.999 \\
\text { WFI: } R^{2}=1 \\
\text { Buffer: } R^{2}=0.999\end{array}$ & $\begin{array}{l}\text { NS: } R^{2}=0.999 \\
\text { WFI: } R^{2}=0.998 \\
\text { Buffer: } R^{2}=0.997\end{array}$ \\
\hline Intra-day precision $(n=5)$ & $\begin{array}{l}\text { NS: } c V=1.1 \% \\
\text { WFI: } c V=1.3 \% \\
\text { Buffer: } c V=0.7 \%\end{array}$ & $\begin{array}{l}\text { NS: } 0.4 \% \\
\text { WFI: } 1.7 \% \\
\text { Buffer: } 1.9 \%\end{array}$ & $\begin{array}{l}\text { NS: } 1.6 \% \\
\text { WFI: } 1.4 \% \\
\text { Buffer: } 2.2 \%\end{array}$ \\
\hline Inter-day precision $(n=5)$ & $\begin{array}{l}\text { NS: } \mathrm{cv}=1.9 \% \\
\text { WFI: } \mathrm{cv}=3.5 \% \\
\text { Buffer: } \mathrm{cV}=1.5 \%\end{array}$ & $\begin{array}{l}\text { NS: } c v=2.5 \% \\
\text { WFI: } c v=0.4 \% \\
\text { Buffer: } c v=2.3 \%\end{array}$ & $\begin{array}{l}\text { NS: } c v=2.2 \% \\
\text { WFI: } c v=3.1 \% \\
\text { Buffer: } c v=3.9 \%\end{array}$ \\
\hline
\end{tabular}

${ }^{a}$ Applicable to all diluents.

Linearity was evaluated around the expected concentration range. A correlation coefficient $\left(R^{2}\right)>$ 0.99 was indicative of linearity when combined with visual inspection of the plot.

\section{Chemical basis of the detergents (formulations)}

A range of detergents (acid, neutral, alkali) was used in the study. The importance of their use is that, unlike single chemical solutions, all detergents used are composed of a series of components - such as acid/alkali/neutral base, $\mathrm{pH}$ regulators, oxidizing agents, chelators, surfactants and solubilizing agents - which work together to not only clean a specific target soil, such as protein from a surface, but to provide an optimum environment for the cleaning agents to work. Major components of the acidic formulations used were hydroxyacetic acid (CIP 220), phosphoric and citric acid (CIP 200), citric acid (Cage-Klenz). The neutral formulations, such as Renu-Klenz and NpH-Klenz, and the alkaline formulation, Criti-Klenz, contain high levels of surfactants, whereas the remaining alkaline formulations were potassium hydroxide, sodium hypochlorite (CIP 150) and potassium hydroxide (CIP 100) based.

\section{Phase I: physical removal by detergents}

The ability of eight detergents was investigated for their effects when used in a wipe study to physically remove dried cytotoxic drug from the test surface. WFI and IMS were used as the controls. For each detergent, $50 \mu \mathrm{L}$ was pipetted onto a cytotoxic-coated surface and control test surface. Wiping involved one stroke across the test surface. The area was wiped immediately. If the drug remained on the surface, ie, the amount remaining was above the limit of detection of the method, a second surface of the same drug was wiped twice. If still above the limit of detection, a third surface of the same drug was wiped three times. The remaining drug was then recovered from the wiped test surface and analysed by HPLC.

\section{Phase II: deactivation by detergents}

The ability of the same eight detergents to degrade the three cytotoxic drugs was investigated using a modification of the suspension test, as set out in British Standard (BS EN 1656; 2000; 22). A 35\% (Vaprox ${ }^{\circledR}$ ) liquid hydrogen peroxide solution was also included to compare with the gaseous activity. A solution $(100 \mu \mathrm{L})$ of test drug was mixed with an equal volume $(100 \mu \mathrm{L})$ of diluted detergent or Vaprox ${ }^{\circledR}$ at room temperature. The solution was vortexed for 1 minute, then incubated at $22-23^{\circ} \mathrm{C}$ for up to 60 minutes. Following incubation, $800 \mu \mathrm{L}$ of HPLC assay buffer was added to terminate the action of the detergent. IMS was used as a control. The amount of parent drug remaining in the resulting mixture was quantified by HPLC. The drugs were subjected to extreme levels of $\mathrm{pH}$, ranging from 1.7 to 13.2 (Table 2).

\section{Phase III: deactivation by VHP ${ }^{\circledR}$}

VHP ${ }^{\circledR}$ delivery and control systems have been developed to provide a consistent fumigation process for a given area. ${ }^{23} \mathrm{VHP}^{\circledR}$ was generated using $35 \%$ liquid hydrogen peroxide (Vaprox $\left.{ }^{(}\right)$inside a VHP ${ }^{\circledR}$ 
Table 2. Dilution and $\mathrm{pH}$ of detergents, Vaprox ${ }^{\circledR}$ and IMS

\begin{tabular}{lcccccccccc}
\hline & \multicolumn{10}{c}{ Detergents } \\
\cline { 2 - 10 } & CIP 100 & CIP 150 & Criti-Klenz & Renu-Klenz & NpH-Klenz & CIP 220 & Cage-Klenz & CIP 200 & Vaprox ${ }^{\circledR}$ & IMS \\
\hline Dilution (\%) & 0.8 & 0.8 & 1.6 & 1.6 & 1.6 & 1.6 & 1.6 & 1.6 & 35 & 70 \\
$\mathrm{pH}$ & 13.2 & 12.8 & 11.3 & 8.0 & 7.5 & 2.4 & 2.3 & 1.7 & 2.6 & 5.5 \\
\hline
\end{tabular}

${ }^{a}$ All reagents used were diluted in distilled water based on manufacturers instructions, except for Vaprox ${ }^{\circledR}$.

$100 \mathrm{P}$ bio-decontamination system. The $\mathrm{VHP}^{\circledR} 100 \mathrm{P}$ is a mobile system which, when connected to a given area, controls the whole dry fumigation process (Figure 1). A typical $\mathrm{VHP}^{\circledR}$ decontamination cycle consists of four phases: dehumidification, conditioning, decontamination and aeration (cycle conditions are given in Table 3). The exposure was carried out in a flexible walled isolator with an area of $1 \mathrm{~m}^{3}$. Prior to each cycle, a leak test was carried out to ensure that the flexible isolator was leak proof. Chemical indicators were placed evenly within the isolator to confirm an even distribution of $\mathrm{VHP}^{\circledR}$. During the course of the cycle, room and isolator temperatures were monitored for signs of condensation within the isolator. If condensation appeared, the cycle was aborted. Following exposure to $\mathrm{VHP}^{\circledR}$, the drug was recovered from the test surfaces and quantified by HPLC.

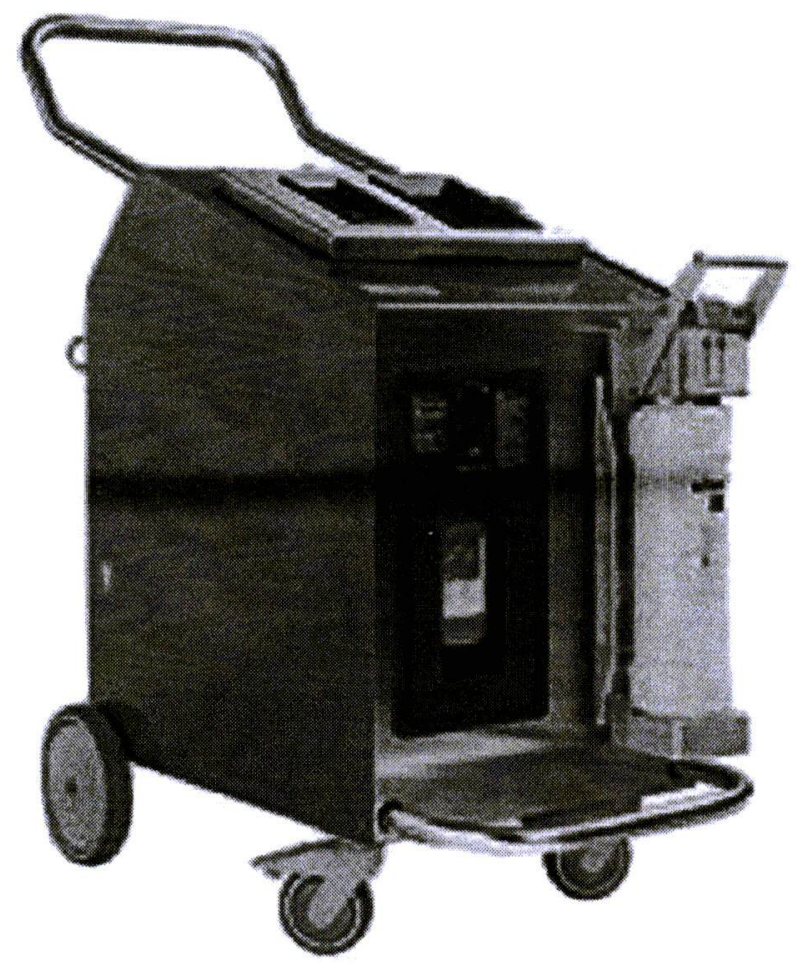

Figure 1. Front view of a mobile VHP 100P unit, which delivers dry hydrogen peroxide vapour.

\section{RESULTS}

\section{HPLC method validation}

Validated HPLC methods for all three drugs in three diluents were used to quantify the amount of drug remaining after each test (Table 1).

Recovery from the drug-coated surfaces was very high (>95\%). The methods are reproducible with a coefficient of variation of $<2.2 \%$ for intra- and $<3.9 \%$ inter-day precision. This applies to all three drugs in three diluents.

Linearity was demonstrated over the concentration range of $0.5-30 \mu \mathrm{g} / \mathrm{mL}$ for $5-\mathrm{FU}, 10-700 \mu \mathrm{g} / \mathrm{mL}$ for $\mathrm{CP}$, and $1-20 \mu \mathrm{g} / \mathrm{mL}$ for DOX. Peak area $(y)$ plotted against concentration $(\boldsymbol{x})$ gave a correlation coefficient $\left(R^{2}\right)>0.99$, demonstrating a linear relationship between $x$ and $y$.

Phase I: physical removal by detergents

5-FU and CP were easily removed from the test surface when using a dry wipe, with acid, neutral or alkaline detergent (Table 4). DOX was easily removed with acid or neutral detergent, but was more persistent to removal by alkaline detergents, requiring more than one wipe to remove all traces (not quantifiable).

Table 3. $\mathrm{VHP}{ }^{\circledR}$ cycle parameters

\begin{tabular}{lc}
\hline Parameter & Value \\
\hline Dehumidification & \\
- Airflow $\left(\mathrm{m}^{3} / \mathrm{h}\right)$ & 18 \\
- Absolute humidity $(\mathrm{mg} / \mathrm{L})$ & 2.3 \\
- Time $(\mathrm{min})$ & 10 \\
Conditioning & \\
- Airflow $\left(\mathrm{m}^{3} / \mathrm{h}\right)$ & 12 \\
- Injection rate $(\mathrm{g} / \mathrm{min})$ & 2.5 \\
- Time $(\mathrm{min})$ & 3 \\
Decontamination & 12 \\
- Airflow $\left(\mathrm{m}^{3} / \mathrm{h}\right)$ & 1.6 \\
- Injection $\mathrm{rate}(\mathrm{g} / \mathrm{min})$ & 25 \\
Aeration & \\
- Airflow $\left(\mathrm{m}^{3} / \mathrm{h}\right)$ & 18 \\
- Time $\left(\mathrm{min}^{\mathrm{m}}\right)$ & 90 \\
\hline
\end{tabular}


Table 4. Decontamination by detergents (removal by wiping)

\begin{tabular}{lcccccc}
\hline Test & \multicolumn{5}{c}{ No. of wipes required to remove drug } \\
\cline { 2 - 7 } & 5-FU (WFI) & 5-FU (NS) & CP (WFI) & CP (NS) & DOX (WFI) & DOX (NS) \\
\hline WFI & 1 & 3 & 1 & 1 & 1 & 1 \\
Criti-Klenz & 1 & 1 & 1 & 1 & 2 & 2 \\
CIP 150 & 1 & 1 & 1 & 1 & 2 & 3 \\
CIP 100 & 1 & 1 & 1 & 1 & 1 & 2 \\
Renu-Klenz & 1 & 1 & 1 & 1 & 1 & 1 \\
NpH-Klenz & 1 & 1 & 1 & 1 & 1 & 1 \\
Cage-Klenz & 1 & 1 & 1 & 1 & 1 & 1 \\
CIP 220 & 1 & 1 & 1 & 1 & 1 & 1 \\
CIP 200 & 1 & 1 & 1 & 1 & 1 \\
IMS & 1 & 1 & & 1 & 1 \\
\hline
\end{tabular}

An immediate colour change from red to purple was evident when the three alkaline detergents were added to DOX. The depth of purple increased with increasing alkalinity of the detergents. This colour change was not observed with the controls (WFI and IMS).

Wiping with WFI and IMS was effective in removing all three drugs. All detergents were superior over WFI when removing 5-FU diluted in NS.

\section{Phase II: deactivation by detergents}

5-FU and $\mathrm{CP}$ demonstrated resistance to decomposition across the $\mathrm{pH}$ range following 60 minutes of exposure to all detergents and liquid hydrogen peroxide. DOX was resistant to degradation at acid and neutral $\mathrm{pH}$ up to and including 60 minutes. However, significant degradation of DOX was observed with alkaline detergents, the rate increasing with increasing alkalinity. The rate of degradation of DOX by alkaline detergents is shown in Figure 2 .

The rate of degradation of DOX can be described by the equation $y=-0.0089 x+1.9773, R^{2}=0.934$, and has a half-life of 31.3 minutes when exposed to Criti-Klenz.

Degradation by CIP 150 can be described by the equation $y=-0.0055 x+1.8847, R^{2}=0.904$, with a halfulfe of 33.A minutes. Degradation by CID 100 can be described by the equation $y=-0.009 x+1.7485$, $R^{2}=0.847$, with a half-life of 5.5 minutes.

A colour change from red to deep purple was also observed upon the addition of alkaline detergents to DOX. The depth of purple increased with increasing $\mathrm{pH}$ of the detergents. This was not observed with acidic- or neutral-based detergents or IMS. Temperatures, which did not exceed $24^{\circ} \mathrm{C}$ throughout the study, had no effect on the controls and, therefore, did not contribute to any degradation. All three drugs showed no degradation after exposure to liquid hydrogen peroxide for 60 minutes.

\section{Phase III: deactivation by VHPP}

The decontamination cycle with the $\mathrm{VHP}^{\circledR}$ was successfully completed. All chemical indicators changed colour from blue to beige during the exposure of all three drugs tested, demonstrating the presence of $\mathrm{VHP}^{\circledR}$ throughout the flexible isolator and the use of a successful validated cycle. Internal isolator temperature readings did not rise above $30^{\circ} \mathrm{C}$, and external air temperature did not rise above $28^{\circ} \mathrm{C}$. No condensation was predicted or evident inside the isolator at any point throughout the duration of the exposures. VHP ${ }^{\circledR}$ had no effect on the blank and control test surfaces in the study. Furthermore, there was no evidence of degradation of DOX in control test surfaces from the effect of natural light or temperature throughout the cycle duration (Table 5).

$\mathrm{VHP}^{\circledR}$ had little or no effect on 5 -FU under the conditions tested. The peak area of all measurements was slightly lower than the range of accuracy of the method, but no degradation products or significant decrease in LC peak height was observed. Similarly, $\mathrm{VHP}^{\circledR}$ had no significant effect on CP. The peak area of CP diluted in buffer was slightly lower than the range of intra-day accuracy of the method; but no degradation product or decreane in peak hoight wan observed. VHP ${ }^{\circledR}$ did cause significant degradation of DOX. The amount of degradation was dependent on the diluent used, ie, $43.4 \%$ degradation with WFI ( $\mathrm{pH}$ 5.9), 56.0\% with NS (pH 6.5), and $91.9 \%$ with buffer (pH 2.25). No colour change of DOX was observed with VHP ${ }^{\circledR}$ exposure.

Figure 3 shows a chromatogram of DOX in buffer pre-exposure (upper chromatogram) and post-exposure (lower chromatogram) to $\mathrm{VHP}^{\circledR}$. Degradation products were not identified or quantified. 


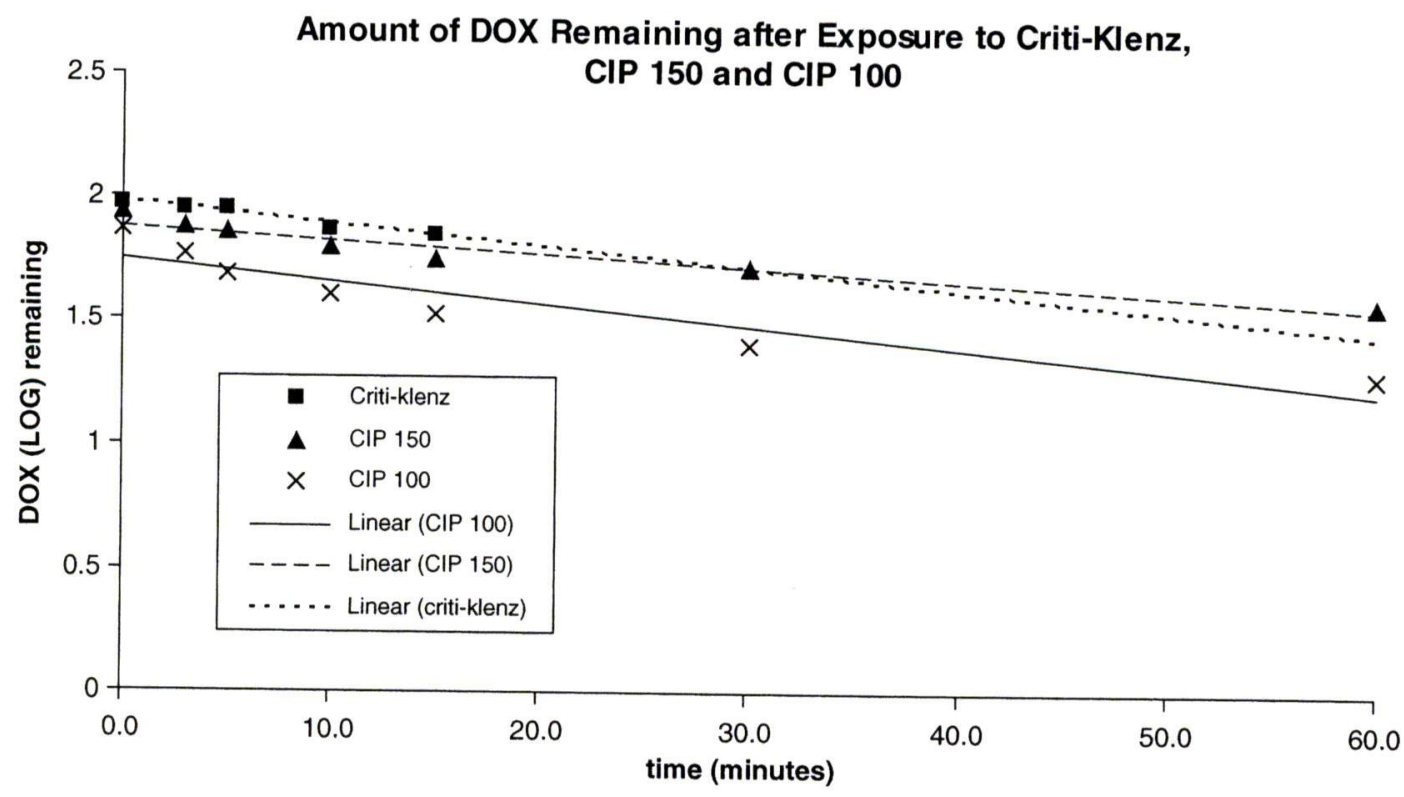

Figure 2. Amount of doxorubicin remaining after exposure to alkaline detergents.

\section{CONCLUSION AND DISCUSSION}

Many cytotoxic drugs are manipulated in clinical practice and reports of contamination by aerosols, spillages and droplets are highlighted in the literature. ${ }^{3,8}$ This study was set up as a pilot study to investigate the effect of current decontamination technologies $\left(\mathrm{VHP}^{\circledR}\right.$ fumigation and liquid detergents) as potential agents which could reduce the risk to the operator by reducing or eliminating drug contamination from a surface.

Three different cytotoxic drugs were exposed to detergents (Phase I and II) and VHP ${ }^{\circledR}$ (Phase III). Inert polypropylene test surfaces were coated with

Table 5. VHP ${ }^{\circledR}$ exposure assay results

\begin{tabular}{llc}
\hline Drug & \multicolumn{1}{c}{ Exposure } & $\begin{array}{c}\text { Drug remaining after } \\
\text { exposure (\%) }\end{array}$ \\
\hline 5-FU in WFI & VHP & 97.9 \\
$5-F U$ in NS & VHP & 96.5 \\
5-FU in buffer & VHP & 99.1 \\
CP in WFI & VHP & 98.7 \\
CP in NS & VHP & 97.7 \\
CP in buffer & VHP & 94.1 \\
DOX in WFI & VHP & 56.6 \\
DOX in WFI & Control (light) & 102.4 \\
DOX in WFI & Control (temperature) & 101.0 \\
DOX in NS & VHP & 44.0 \\
DOX in NS & Control (light) & 98.9 \\
DOX in NS & Control (temperature) & 100.0 \\
DOX in bufter & Vitp & 9.1 \\
DOX in buffer & Control (light) & 90.1 \\
DOX in buffer & Control (temperature) & 97.9 \\
\hline
\end{tabular}

the drugs for Phases I and III. High recovery methods from the test surfaces, together with reliable HPLC methods, were developed, validated and successfully used to quantify the amount of drug remaining after testing in this study.

Preliminary wipe tests using strong alkaline, acid, or neutral detergents, and wiping with a dry wipe removed all three drugs from a contaminated surface. WFI and IMS, the controls, were also efficient. DOX was more persistent to removal, but less persistent to breakdown (indicated by a colour change) by alkaline detergents. The depth of colour change was alkaline$\mathrm{pH}$ dependent.

Exposure of drug solution for up to 1 hour in strong acid and alkali and neutral-based detergents caused no degradation of 5-FU and CP. Degradation of DOX occurred when it was subjected to alkaline $\mathrm{pH}$ following 1 hour of incubation. This resulted in 81\% degradation at $\mathrm{pH} 13.2$, with $50 \%$ occurring after 5.5 minutes.

The results showed that $\mathrm{VHP}^{\circledR}$ had little to no significant effect on 5-FU or CP, however, degradation was observed with DOX. The degree of degradation was dependent on the diluent used, with significant degradation obtained when DOX was exposed following dilution in a strongly acidic buffer $(\mathrm{pH} 2.25)$. Further studies are in progress to investigate the effects of $\mathrm{VHP}^{\circledR}$ over longer exposure times and higher concentrations against all three drug types. It is interesting to note that liquid hydrogen peroxide, in contrast to gaseous peroxide had no effect on drug 


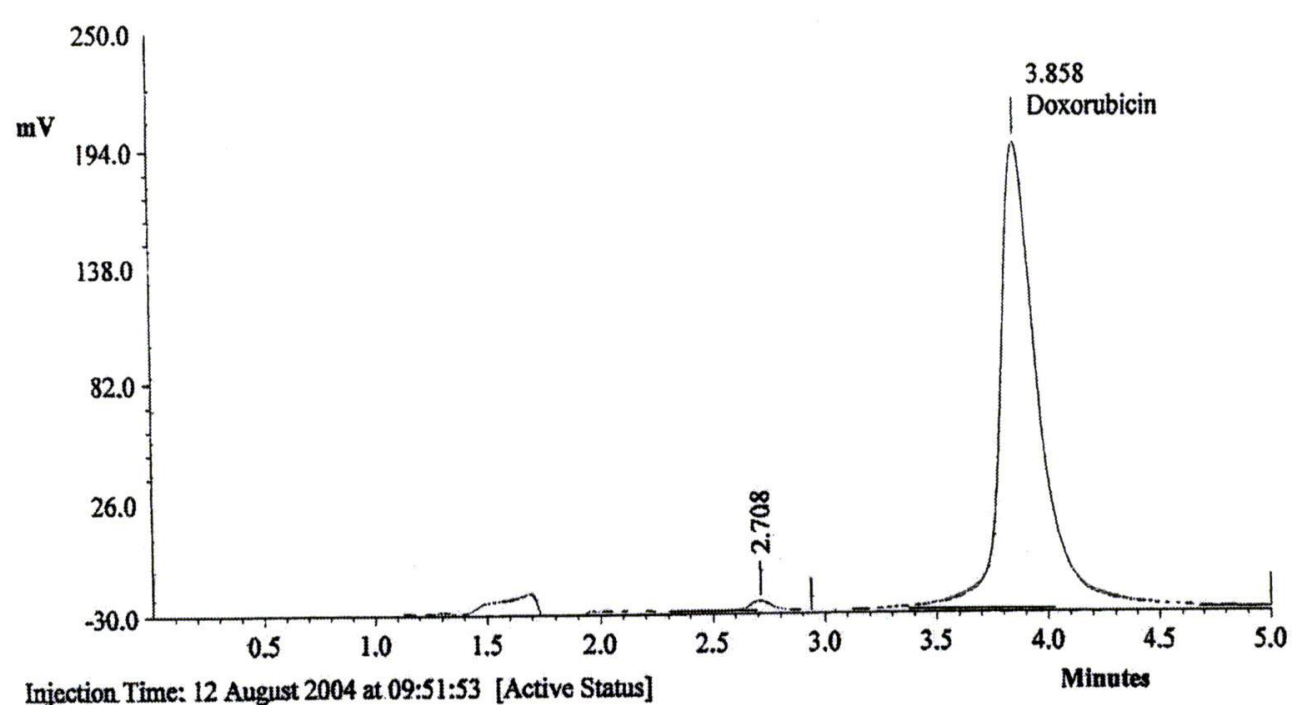

Injection Time: 12 August 2004 at 09:51:53 [Active Status]

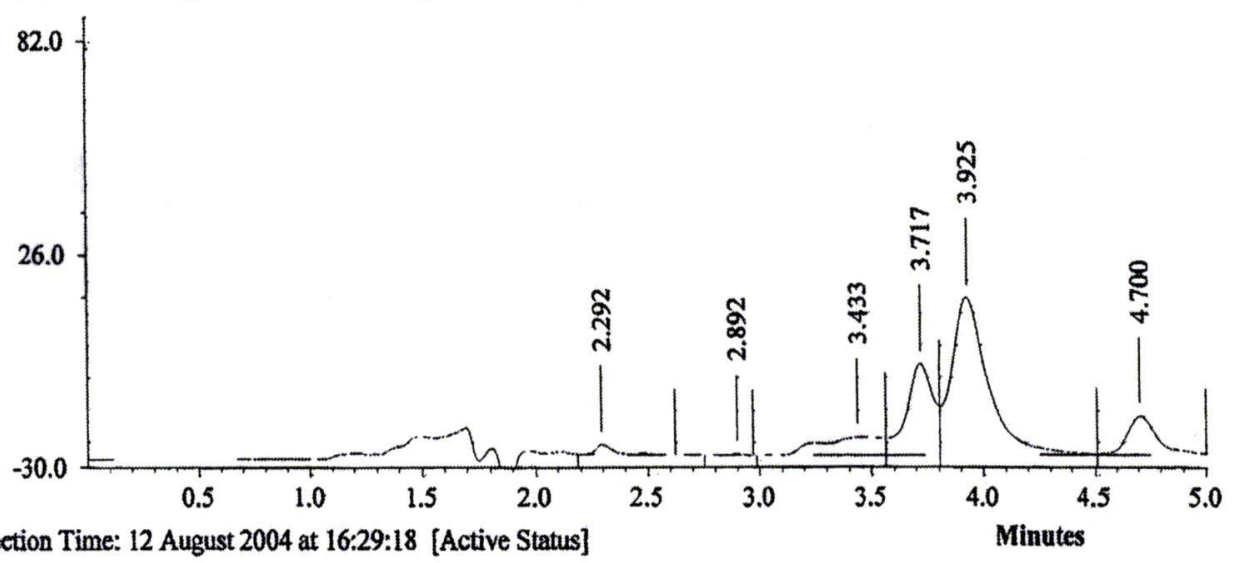

Figure 3. Example of a chromatogram of doxorubicin diluted in buffer, pre- and post-exposure to VHP ${ }^{\circledR}$.

decomposition. The gaseous form of peroxide has been proposed to be a more effective oxidizing agent due to its unstable nature compared to liquid peroxide. $^{26}$

This study confirms the stability of 5-FU and CP to oxidative stress, since no decomposition occurred during exposure to gaseous and liquid hydrogen peroxide, even when exposed to extreme $\mathrm{pH}$ conditions ( $\mathrm{pH}$ 1.7-13.2) applied. DOX, however, was found to be less stable. The susceptibility of DOX to oxidation is reported in the literature, ${ }^{24}$ it is also unstable at $\mathrm{pH}$ values $<3$ or $>7 . .^{25}$ In this study, DOX was susceptible to oxidation by $\mathrm{VHP}^{\circledR}$, and its instability at lower $\mathrm{pH}$ confirmed.

Exposure of DOX to alkaline-based liquid agents resulted in a colour change from red to purple, which is indicative of decomposition. DOX was susceptible to both $\mathrm{VHP}^{\circledR}$ and alkaline agents, indicating that the degradation of DOX was occurring through two different mechanisms, oxidation as one method and alkali hydrolysis as the other method. No colour change was evident with oxidation.

The results presented are not in total agreement with the literature. ${ }^{16,17}$ Sodium hypochlorite $(5.25 \%)$ and $<30 \%$ hydrogen peroxide have been reported to exhibit $>98 \%$ efficiency in inactivating CP after 1 hour of exposure. DOX was also completely degraded by sodium hypochlorite. The detergent CIP 150 also contains sodium hypochlorite $(<5 \%)$, however, no effect was observed on CP or DOX with CIP 150 , or on CP with the $35 \%$ liquid hydrogen peroxide used in this study. These results should be investigated further.

Phase I was carried out following a review of drug structures. Alkaline hydrolysis appeared to be the likely method of degradation of 5-FU in solution. A range of alkaline-based detergents was tested. Degradation of 5-FU through alkaline hydrolysis is reported to be a slow process, leading to the formation of barbituric acid, which degrades 
more rapidly than it is formed, and uracil, which further degrades to urea. ${ }^{27}$ None of the degradation products are cytotoxic. The rate of alkaline hydrolysis increases above $\mathrm{pH} 9.0 .^{24}$ Thermal and photochemical degradation causes opening of the pyrimidine ring to produce urea. To date, there is no satisfactory method for the deactivation of 5-FU.

CP degradation occurs primarily by hydrolysis in aqueous solution. The rate is constant over the $\mathrm{pH}$ range $2-10$. Specific acid and specific base catalysis occurs at extreme $\mathrm{pH}^{27}$ Under acidic conditions, hydrolysis may occur by different pathways. The pathway and breakdown products formed depend upon the $\mathrm{pH}$ of the solution. ${ }^{27}$ Under basic or neutral conditions, hydrolysis occurs by an initial intramolecular alkylation, forming a bicyclic compound and hydrochloric acid. ${ }^{27}$ However, this compound is very labile in aqueous solution and may breakdown to further products. ${ }^{27} \mathrm{CP}$ is temperature sensitive and hydrolysis may occur rapidly at temperatures above $30^{\circ} \mathrm{C}$.

DOX exhibits pH-dependent stability in solution. It is sensitive to light and temperature. In solutions of $\mathrm{pH}<4$, the glycosidic bond is cleaved, releasing a red water-soluble amino sugar (daunosamine), ${ }^{25}$ and a water-insoluble tetracyclic aglycone (doxorubicinone). The aglycone is cytotoxic, but less so than the parent drug. ${ }^{24}$

In alkaline solution, a colour change from red to deep purple is due to rapid degradation of the drug. ${ }^{24}$ It is thought to reflect cleavage of the amino sugar and the formation of other degradation products, such as 7,8-dehydro-9,10 desacetyl-daunorubicnone. ${ }^{24}$ This colour change also occurs with the other anthracyclines antibiotics which are structurally similar. ${ }^{24,25}$

The results of this study demonstrate that current decontamination methods can be used to reduce, if not eliminate, the risk posed by cytotoxic drugs to the operator and environment. The extent of risk reduction or elimination will vary depending on the structure of the drug. Oxidation and alkaline-based detergents have resulted in the breakdown of DOX by two different mechanisms. Oxidation and alkaline hydrolysis may be used to investigate their effects on drugs of the same anthracycline family as DOX. However, limited success was observed with the chemical deactivation technologies used in this study when applied to drugs representing the other classes, ie, the alkylating agents and the anti-metabolites. Further studies are required to investigate these classes of drugs. The liquid detergents used in this study were formulated for specific target soil. It may be necessary to vary the formulation to target the more stable structures of 5-FU or CP.

The solubility of a drug depends upon the extent to which it is ionized. This is determined by the $\mathrm{pKa}$ of any acidic and basic groups and the $\mathrm{pH}$ of the environment. The drugs are more soluble and likely to be taken up by a wipe at the $\mathrm{pH}$ at which they are $100 \%$ ionized. DOX is ionized at low $\mathrm{pH}$ and was easier to remove from the surface with acid rather than alkali detergents, however alkaline detergents played a part in DOX degradation.

All three drugs used in this study are polar molecules $(\log P<1)$ and were removed from a coated surface by water and aqueous-based detergents. Most cytotoxic drugs are water-soluble, therefore, it is recommended that decontamination is removal by the use of wipes impregnated with an aqueous-based agent, which binds the target drug, followed by disposal of the wipe. A combination of agents will be required to cover removal, ie, it is possible that a high $\mathrm{pH}$ may degrade the drug to compounds that are more soluble and are easier to remove at low $\mathrm{pH}$. Wiping with IMS is common practice, but may also play a part in the removal of less water-soluble drugs and drug degradation products.

From this study, it is suggested that a review of cleaning practices should be carried out and a protocol developed based on the recommendation that after cleaning with water, surfaces should be cleaned with detergent of high $\mathrm{pH}$, followed by detergent of low $\mathrm{pH}$, finally wiping with IMS. VHP is an established process for biological control in isolators and may also be considered, together with other measures, for the control of contamination by drugs that are readily oxidized, such as the anthracyclines.

\section{ACKNOWLEDGEMENTS}

The authors wish to acknowledge the expert help and advice given on the cleaning chemiatries by Mildred R Bernardo, MS Senior Scientist, Steris Corporation, St Louis, USA.

\section{REFERENCES}

1 Connor TH, Anderson RW, Sessink PJM, et al. Surface contamination with antineoplastic agents in six cancer treatment centres in Canada and the United States. Am J Health Sys Pharm 1999; 56: 1427-32. 
2 Floridia L, Pietropaolo AM, Tavazzani M, et al. Highperformance liquid chromatography of methotrexate for environmental monitoring of surface contamination in hospital departments and assessment of occupational exposure. J Chromatogr B 1999; 726: 95-103.

3 Hoy RH, Stump MS. Effect of an air-venting filter device on aerosol production from vials. Am J Hosp Pharm 1984; 41: 324-26.

4 Micoli G, Turci R, Arpellini M, Minoia C. Determination of 5-fluorouracil in environmental samples by solid-phase extraction and high-performance liquid chromatography with ultraviolet detection. J Chromatogr B 2001; 750: $25-32$.

5 Schmaus G, Schierl R, Funck S. Monitoring surface contamination by antineoplastic drugs using gas chromatography-mass spectrometry and voltammetry. Am J Health Sys Pharm 2002; 59: 956-61.

6 Sessink PJM, Anzion RBM, Petra HH, Bos RP. Detection of contamination with antineoplastic agents in a hospital pharmacy department. Pharm Weekbl Sci Ed 1992; 14: 16-22.

7 Sessink PJM, Boer KA, Scheefhals APH, et al. Occupational exposure to antineoplastic agents at several departments in a hospital. Int Arch Occup Environ Health 1992; 64: 105-12.

8 Spivey PJ, Connor TH. Determining sources of workplace contamination with antineoplastic drugs and comparing conventional IV drug preparation with a closed system. Hosp Pharm 2003; 38: 135-39.

9 Vandenbroucke J. Cytotoxic agents and contamination in hospitals: a monitoring program in Uz Gent. $J$ Oncol Pharm Pract 2001; 6: 146-52.

10 Selevan SG, Lindbohm M-L, Hornung RW, Hemminki K. A study of occupational exposure to antineoplastic drugs and fetal loss in nurses. New Engl J Med 1985; 313: $1173-77$.

11 Shortridge LA, Lemasters GK, Valanis B. Menstrual cycles in nurses handling antineoplastic drugs. Cancer Nurs 1995; 18: 439-44.

12 Skov $\mathrm{T}$, Maarup B, Olsen J, et al. Leukemia and reproductive outcome among nurses handling antineoplastic drugs. Br J Int Med 1992; 49: 855-61.

13 Valanis B, Vollmer WM, Steele P. Occupational exposure to antineoplastic agents; self-reported miscarriages and stillbirths among nurses and pharmacists. $J$ Occup Environ Med 1999; 41: 632-38.

14 NIOSH Alert. 2004. Retrieved from http://www.cdc.gov/ niosh/docs/2004-165/
15 World Health Organisation. Laboratory decontamination and destruction of carcinogens in laboratory wastes; some antineoplastic agents. International Agency for Research on Cancer, 1985 (IARC publication No.: 73 2004).

16 Castegnaro $\mathrm{M}$, De Meo MD, Laget $\mathrm{M}$, et al. Chemical degradation of wastes of antineoplastic agents. 2: Six anthracyclines: idarubicin, doxorubicin, epirubicin, pirarubicin, aclarubicin and daunorubicin. Int Arcb Occup Environ Health 1997; 70: 378-84.

17 Hansel S, Castegnaro M, Sportouch MH, et al. Chemical degradation of wastes of antineoplastic agents: cyclophosphamide, ifosfamide and melphalan. Int Arch Occup Environ Health 1997; 69: 109-14.

18 Klapes NR, Vesley D. Vapor-phase hydrogen peroxide as a surface decontaminant and sterilant. Appl Environ Microbiol 1990; 56: 503-506.

19 Krause J, McDonnell G, Riedesel H. Biodecontamination of animal rooms and heat sensitive equipment with vaporised hydrogen peroxide. Contemporary topics. Am Assoc Lab Anim Sci 2001; 40:18-21.

20 Analytical method for cyclophosphamide. Clinical Pharmaceutics Laboratory, Pharmacy Department, Bath University, 2002.

21 Analytical method for doxorubicin. Clinical Pharmaceutics Laboratory, Pharmacy Department, Bath University, 2004.

22 Roberts S, Sewell GJ. Stability and compatibility of 5-fluorouracil infusions in the Braun Easypump. J Oncol Pharm 2003; 9: 2-3.

23 Bressolle F, Bromet-Petit M, Audran M. Validation of liquid chromatography and gas chromatographic methods. Applications to pharmacokinetics. $J$ Chromatogr $B$ 1996; 686: 3-10.

24 Allwood M, Stanley A, Wright $\mathrm{P}$ eds. The cytotoxics handbook, fourth edition. Radcliffe Medical Press, 2006.

25 Trissel LA. The handbook of injectable drugs. American Society of Health System Pharmacists 2005.

26 McDonnell G. Peroxygens and other forms of oxygen. In Zhu $\mathrm{P}$ ed. New biocides development: the combined approach of chemistry and microbiology. ACS Books, Oxford University Press, Washington D.C. 2006.

27 Connors KA, Amidon GL, Stella J. Chemical stability of pharmaceuticals. A bandbook for pharmacists, second edition. J. Wiley \& Sons Inc 1986. 